\title{
EXPLORING FOUR DIMENSIONS OF ONLINE INSTRUCTOR ROLES: A PROGRAM LEVEL CASE STUDY
}

\author{
Xiaojing Liu \\ Kelley Direct Online Programs \\ Indiana University \\ Curt J. Bonk \\ Department of Instructional Systems Technology \\ Indiana University \\ Richard J. Magjuka \\ Chair of Kelley Direct Online Programs \\ Indiana University
}

\author{
Seung-hee Lee \\ Kelley Direct Online Programs \\ Indiana University \\ Bude Su \\ Department of Instructional Systems Technology \\ Indiana University
}

\begin{abstract}
The purpose of this study was to understand the practice of online facilitation in a Midwestern university which has a highly successful traditional MBA program. This study explored the instructors' perceptions regarding four dimensions of instructor roles using Berge's [1] classifications: pedagogical, managerial, social, and technical. This study also examined the challenges and issues confronting online instructors when fulfilling these roles. The results suggest that instructors carried out several important roles to varying degrees. The findings reveal a stronger emphasis on the pedagogical roles (course designer, profession-inspirer, feedback-giver, and interaction-facilitator). Emphasizing those roles, the instructors promote three types of interactions: student-content, student-student, and student-teacher. A lesser emphasis on social roles represented mixed feelings regarding its importance to the instructors. While students rated the instructors very positively, the results also indicate that instructors still need to have their roles transformed pedagogically, socially, and technologically if they are to establish a more engaging and fruitful environment for online learning.
\end{abstract}

\section{KEYWORDS}

Instructor Roles, Online Learning, Facilitation, Pedagogical Role, Managerial Role, Social Role, Technical Role

\section{INTRODUCTION}

With the development of new and emerging technologies, the values and beliefs underlying the teaching and learning process are being reconceived. As online learning gains wider acceptance in higher education, there is an increasing awareness of the facilitative roles of instructors in virtual space. The facilitative role is especially important when students are required to engage in complex learning tasks. In fact, Morine-Dershimer [2] found that instructor guidance nurtures a richer understanding of complex problems by enabling students to process a greater complexity of information. 
One of the key challenges facing online instructors is how to provide clear and visible guidance in a virtual environment. In the traditional classroom, facilitation relies on both verbal and non-verbal cues to initiate understanding of ongoing communication and course tasks. Communication online, however, relies mainly on written language without paralinguistic cues. Changes in communication patterns require instructors to adapt personal perceptions of their roles to adjust to an online learning environment that keeps remotely distributed learners continuously engaged in the learning process [3]. A large body of literature argues that the new roles of online instructors may be more complicated than in traditional classrooms [4, 5]. Meanwhile, the emergence of new technologies makes it increasingly easier to involve distant learners in two-way communications, thereby enabling self-directed learners to construct meaning socially [6]. The culture of higher education is moving away from teacher-centered learning towards learner-directed learning, with instructors functioning as facilitators, coaches, consultants, or resource people who provide intellectual guidance for student learning [6, 7].

A comprehensive classification, first proposed by Berge [1], then expanded by Ashton, Roberts, and Teles [8] as well as Bonk, Kirkley, Hara, and Dennen [9], describes the multiple roles of online instructors in four dimensions: (1) pedagogical, (2) social, (3) managerial, and (4) technical. While there is a growing body of literature that emphasizes the importance of instructor roles in distance learning, few empirical studies have examined the issues that instructors face in their new roles. Ashton et al. [8] suggest future research should examine the four dimensions of online instructor roles across different instructors, across different courses, and from the beginning to end of online courses. The results reported in this study extend previous findings regarding the facilitative roles of online instructors by examining pedagogical, social, managerial, and technical roles across instructors in an online program.

The purpose of this research was to examine the most important concerns and issues linked to the four dimensions of online instructor roles in a rapidly-expanding online MBA program. This study will focus on the following research questions:

- What are instructors' perceptions of their roles when teaching online in terms of Berge's [1] classifications?

- What are students' perceptions of four dimensions of instructor roles?

By examining these questions, we will be able to understand the salient contextual factors that affect how different roles are enacted by online instructors. Such examinations of contextual factors are helpful in providing valuable insights and implications for developing strategic program support for online learning environments.

\section{THEORETICAL REVIEW}

In the present study, Berge's instructor roles—pedagogical, managerial, social, and technical—have been used as a framework to organize the literature on the varied duties of the online teacher as well as the key findings of this study.

\section{A. Pedagogical Role}

The pedagogical roles of online instructors revolve around facilitating educational processes for students' understanding of critical concepts, principles, and skills [1]. Such tasks include encouraging students' knowledge-sharing and knowledge-building through interactive discussion, designing a variety of educational experiences, providing feedback, and referring to external resources or experts in the field [8, 9]. Similarly, Salmon [10] elaborated the important role of facilitators as "weavers" who facilitate an 
effective online discussion by weaving statements and relating them to relevant concepts and theories so as to enable the development of ideas through collaborative discourse. High quality instructions require that instructors have online moderation skills. Oftentimes a variety of pedagogical roles have to be performed to facilitate higher order thinking skills. For example, to facilitate effective online debate, the instructors need to identify controversial topics, encourage and balance discussion on both sides, provide additional evidence and counter examples, and summarize and weave online discussion to raise debates to higher and more personally engaging levels [7, 11].

A variety of tasks have been identified for developing the metacognitive skills of online learners, such as goal-setting, self-monitoring, and evaluation, as well as identifying self-motivating factors and enabling the self-direction of participants $[4,12,13]$. Though different researchers emphasize different aspects of pedagogy, the scope of the pedagogical roles has been increasingly expanded to include a wide range of tasks that contribute to the understanding of course content as well as the development of critical thinking skills for online learners.

\section{B. Social Role}

The social function is typically employed to promote a friendly environment and community feelings to support student cognitive learning processes. Such social functions include developing harmony, group cohesiveness, and collective identity $[1,8,9]$. Online social roles require instructors to develop nurturing skills by encouraging participation, giving ample feedback and reward, attending to individual concerns, and using a friendly, personal tone [14]. In a learning community, participants have a strong sense of belonging and are ready and willing to contribute to the knowledge building of a larger community [15, 16]. Not only do instructors need to establish a leadership role in nurturing community, they also are expected to model the social roles to online students to motivate and engage students in a community of inquiry [17]. Studies have found that a weak sense of social cohesiveness could result in increasing the drop-out rate of online students who feel isolated and stressed [18].

Though social roles have been widely cited in recent research, studies have indicated that instructors who are new to teaching online may have difficulty getting used to new social roles. Conrad's [19] study noted that inexperienced online instructors often lacked essential social skills and preferred personalized communication instead of taking leading roles in establishing a wider community; it may be difficult to understand the importance of social roles when instructors discover just how task-oriented online students are [5].

\section{Managerial Role}

Managerial roles include the organizational, procedural, and administrative tasks associated with the learning environment [1]. The tasks involve coordinating assignments, managing online discussion forums, and handling overall course structure [8,9]. Mason [20] advocates that online instructors take strong leadership in shaping online interaction by setting clear agendas and objectives for online conferences and establishing procedural rules and decision-making norms. Studies support using clearly structured content and timetables to lay out the expectations to improve the quality of online discourse [21], and setting clear expectations for online interactions prior to the beginning of the course to facilitate a positive learning experience [4].

The evolving nature of managerial roles has been observed in several studies. For instance, Teles, Ashton, Roberts, and Tzoneva [22] found that more managerial issues may be involved in the earlier stages of online courses before new instructors gain extensive online experience. A study by Conrad [19] found 
that many managerial roles, such as setting objectives and making rules, may be tempered by welldesigned course templates. Managerial roles are necessary for maintaining a successful online learning environment.

\section{Technical Role}

Early studies indicated that technical difficulty was one of the most significant causes of students' dissatisfaction with web-based courses [23]. The technical role of online instructors can make participants comfortable with the system and software program used for online courses. Technical tasks include referring students to technical support resources, addressing technical concerns, diagnosing and clarifying problems encountered, and allowing students sufficient time to learn new programs $[1,8,9]$. When the instructor can facilitate a smooth use of technology, the learners will be able to concentrate on the academic task [1]. However, there is little agreement on the importance of the technical role in the literature, in part because technical support can be provided through a variety of ways and in part because there are varying degrees of technology sophistication and use in online courses.

Anderson et al. [17] argued that providing technical assistance is "an onerous function for the online teacher," and the importance of this role decreases as learners and instructors become more experienced online users and as the tools of online learning become more intuitive to use. This argument was supported by several studies [19, 24]. The technical roles of online instructors will constantly change with the advancement of technology and with increased institutional support.

In summary, it is worth mentioning that "not all of these roles need to be carried out in their entirety by the same person. In fact, it may be rare that they are” [1]. Different roles may be intricately related with each other because one issue can cut across two or more areas [1]. When examining the instructors' roles in a naturalistic context, contextual complexities may affect the instructors' role play, including such factors as the time commitment for fulfilling various roles and activities, appropriate skill training, level or type of course, the number of students, and more,

\section{METHODOLOGY}

The purpose of this study was to understand the nature of instructor roles and the complex issues involved in a distance learning environment. The case study approach for such exploratory research is useful for better understanding a complex system like the one studied here [25].

The field setting was an accredited online MBA program at a top ranked business school in a large Midwestern university. The program was designed for professionals who wish to continue their employment while earning their MBA. The faculty pool is drawn from other departments of the business school and features full-time, tenured faculty members. The program has grown to include hundreds of students in just a few years, requiring online faculty instructors to employ many new pedagogical, social, managerial, and technical skills. The researchers believed that such a rapidly expanding program would best illustrate the complexities of instructor roles.

For this study, twenty-eight faculty members were interviewed. Importantly, their subject areas related to all the major disciplines offered in this program. Twenty-seven semi-structured questions were asked, and the interview was conducted in a one-on-one interview. The questions related to the four dimensions of instructor roles, including issues of course delivery and management, pedagogy and motivation, social interaction, and technical support. Each interview took approximately 45 to 75 minutes. 
Strauss and Dorbin's constant comparative method [26] was used to triangulate the data from different interview transcripts and to identify emerging themes under different dimensions of instructor roles. To ensure intercoder reliability, two interview transcripts were coded initially by two researchers, and intercoder agreement achieved 89\% [27]. The researchers then continued coding independently and discussed their coding decisions with each other until a common set of codes based on all the transcripts was determined. All data were recoded again using the ATLAS.ti qualitative analysis software program to determine the frequencies of the different coding categories.

Program evaluation survey data related to students' perceptions of the learning online experience was used to assess students' satisfaction with the four dimensions of online instructors' roles. The student survey instrument consisted of 65 questions. The 65-item survey questionnaire contained 5-point scale Likert type questions about their overall perceptions and attitudes toward learning online. The internal reliability of the survey, Cronbach’s alpha, was .91.

\section{FINDINGS}

\section{A. Instructors' Perceptions on Four Dimensions of Their Roles}

In this section, instructors' perceptions of their roles are described in terms of Berge's four dimensions. Under each dimension, the roles were identified by grouping similar themes associated with that title. A summary of instructor roles is illustrated in Table 1.

Table 1. Summary of Pedagogical, Social, Managerial, and Technological Roles of the Online Instructors

\begin{tabular}{|c|c|c|c|}
\hline Dimensions & Roles & Description of Roles & Issues \\
\hline \multirow[t]{4}{*}{ Pedagogical } & Course designer & $\begin{array}{l}\text { Design interactive learning experience, } \\
\text { structure course materials; refine and } \\
\text { update learning materials; share teaching } \\
\text { experiences with colleagues }\end{array}$ & $\begin{array}{l}\text { Lack of program wide } \\
\text { faculty interaction }\end{array}$ \\
\hline & Profession-inspirer & $\begin{array}{l}\text { Promote professional dialogue among } \\
\text { online learners; relate personal experiences } \\
\text { and cases to the discipline; point to } \\
\text { professional organizations }\end{array}$ & \\
\hline & Feedback-giver & $\begin{array}{l}\text { Provide timely and high quality feedback; } \\
\text { provide formative feedback for continuous } \\
\text { learning engagement }\end{array}$ & \\
\hline & $\begin{array}{l}\text { Interaction- } \\
\text { facilitator }\end{array}$ & $\begin{array}{l}\text { Facilitate peer interaction in online } \\
\text { discussion through a wide range of } \\
\text { facilitation strategies }\end{array}$ & $\begin{array}{l}\text { Lack of facilitation } \\
\text { skills; concerns about } \\
\text { time commitment }\end{array}$ \\
\hline \multirow[t]{2}{*}{ Managerial } & $\begin{array}{l}\text { Conference } \\
\text { manager }\end{array}$ & $\begin{array}{l}\text { Ensure equity in online discussion; provide } \\
\text { rules and guidelines to augment online } \\
\text { discussion; promote knowledge } \\
\text { construction }\end{array}$ & $\begin{array}{l}\text { Lack of skill in weaving } \\
\text { discussion }\end{array}$ \\
\hline & $\begin{array}{l}\text { Organizer and } \\
\text { planner }\end{array}$ & $\begin{array}{l}\text { Provide clear instructions and organization } \\
\text { of course structure; achieve a balance } \\
\text { between structure and flexibility }\end{array}$ & \\
\hline Social & $\begin{array}{l}\text { Social rapport } \\
\text { builder }\end{array}$ & $\begin{array}{l}\text { Build social rapport; establish online teams; } \\
\text { build online learning community }\end{array}$ & $\begin{array}{l}\text { Lack of awareness of } \\
\text { social role; lack of } \\
\text { technology; concern } \\
\text { about time commitment }\end{array}$ \\
\hline \multirow[t]{2}{*}{ Technical } & $\begin{array}{l}\text { Technical } \\
\text { coordinator }\end{array}$ & $\begin{array}{l}\text { Refer students to technical support; } \\
\text { communicate technical issues }\end{array}$ & \\
\hline & Media designer & Develop multi-media tools; identify and co- & Concern about time \\
\hline
\end{tabular}




\begin{tabular}{|l|l|l|l|}
\hline & design efficient learning tools & \\
\cline { 2 - 4 } & $\begin{array}{l}\text { Technology } \\
\text { integrator }\end{array}$ & $\begin{array}{l}\text { Use highly interactive tools to facilitate } \\
\text { high quality online interaction }\end{array}$ & $\begin{array}{l}\text { Lack of technical skills; } \\
\text { concern about time } \\
\text { commitment and } \\
\text { accessibility issues }\end{array}$ \\
\hline
\end{tabular}

\section{Pedagogical Role}

Pedagogical roles can be categorized into four areas: (a) Course designer, (b) Profession-inspirer, (c) Feedback-giver, and (d) Interaction-facilitator.

\section{a. Course Designer}

Many instructors agreed on their "designer" role of repurposing learning materials from the traditional classroom to online courses. Due to the loss of real-time interaction and rich contextual cues that they had experienced in the traditional classroom, it was essential for instructors to provide much more elaborate information in their online courses. As an example of this change, one instructor shared the following:

I'll spend five minutes talking about an experience that I had. It's more difficult to do that with our text files, and that's one of the reasons that I started doing these sound clips, to simulate some of things that I might say in class in addition to, or that would supplement, the slide material. So, enriching the material, the presentation, as much as possible, I think is the most important point.

While selection and design of course material were crucial, many instructors noted that it was equally important to carefully structure and organize the course materials in a way that made students engage in learning through a variety of activities. An instructor commented on the effectiveness of a well-designed structure:

I was delighted at how well that structure, that template went over, just having the discussion forum and the cases, having assignments submitted on the basis of the cases and having support materials. I got very positive feedback.

Many instructors also alluded to the iterative nature or "trial and error" of online course design by continuously refining and improving the assignments, deliverables, or course materials in a way that was both challenging and manageable from the instructor's perspective. An instructor commented on the nature of such iterative design:

You'll find as the students go through that they have difficulty in this area, so you add another paragraph or two in or you take something out to try and improve the course and the communication in it.

The effects of disciplinary differences and the level of courses on the course design were also frequently mentioned by instructors. In fields such as accounting and finance, where models and quantified information are used to make decisions, course design focused more on problem-solving on an individual basis; whereas in other courses such as operations management, multiple perspectives and approaches need to be introduced, and the design was more discussion- and teamwork-oriented.

Instructor design strategies are enhanced when instructors share and discuss their experiences with other instructors who taught the same courses. Instructors worked as a team formally or informally to discuss ideas, share materials, and mentor each other. Additionally, they often provided vital support and encouragement for faculty who were new to teaching online. The interactions of instructors across 
different disciplines were not as high as within each discipline. As one instructor noted:

As for community, I think we're staggering toward one that's driven by the faculty members themselves. The times that we've been in the same room we say to each other, "We've got to get together. We've got to form some kind of group so we can trade ideas." We did get together for a lunch, but it was unplanned, and we can do a lot more with that.

Faculty members in this online MBA program seemed to have identified strongly with their roles as designer. This study indicated these online instructors regarded course design as a vital first step to ensure the quality of online learning. To foster the transition from a highly traditional setting to an online environment, the instructors had carefully thought through the content, structure, and interaction components of their courses, continuously seeking feedback for refining the overall course design [17].

\section{b. Profession-Inspirer}

Helping learners move closer to their professional aspirations is a key goal of professional education. Instructors consistently noted that the nature of online learners, usually already into their careers and more practically-oriented than traditional learners, created a further impetus for structuring learning tasks around real world experiences. A number of instructors noted that they adjusted their assignments and discussions to connect to students' work experience. One instructor commented on professional dialogue among online learners:

I'm just a facilitator to draw out the experiences. So I really spend a lot of time trying to draw from them their experiences and then have other people pick up on what's said and expand that to their environment.

The effectiveness of such engagement was noted by another instructor:

One of the things that I found that I think was pretty effective was when we got off-script on occasion and talked about particular issues that were more practitioner oriented.

This opportunity for applying learning to the real world appeared even more useful when a number of instructors taught company-specific courses such as a Strategic Marketing Management course designed especially for General Motors Corporation. They noted that online courses have the advantage to take learners back to their work contexts and apply the theories on the specific issues they confronted in a company. The following quote illustrates one instructor who took advantage of this opportunity:

The thing that's so unique is that this is an online course, but it's also company-specific. Being company-specific offers a great deal, because then you can have examples, and they can work on real issues that they confront in their company. So, yeah, it's very realworld, because they're talking about their company and their management practices.

\section{c. Feedback-Giver}

Not surprisingly, instructors unanimously agreed on the important role of giving feedback to online learners. They value the immediacy and quality of feedback as well as the sustainability of instructional feedback on students' engagement was valued. Two instructors commented:

I'm a facilitator and I'm a feedback-giver in the online environment. I find what I regard as good material, and I structure assignments that assess their ability to teach themselves. Then, I give detailed feedback on their submitted assignments, and that's where some of the learning comes in. But, basically, I’m assessing how well they’ve learned. 
Deliverables, timely and extensive feedback, and forcing them to do something with that feedback [are essential]. If I'm going to go to the trouble to spend two hours to write them a memo of feedback, I want them to have to take that feedback and use that feedback, rather than spend five minutes reading it over.

The importance of the feedback-giver role reflected, partly, the instructors' perception of the importance of student-instructor interaction and the need for instructors to contribute their knowledge through various ways of giving feedback. On the other hand, instructors also used it as the most important way to pace or control the learning progress of online learners. For example, an instructor commented on how he redesigned the learning tasks for greater interim feedback:

We use fewer cases but in greater depth over a longer period of time with interim submissions by the students and with interim feedback from the faculty. And all of that is our attempt to compensate for the lack of real-time class discussion, so one way to look at it is that we do fewer assignments. But another way to look at it is that we so amplify [those assignments we do] that there's more grading and evaluation.

\section{d. Interaction-Facilitator}

Instructors agreed that online discussion was the key to online interaction. Online discussion promoted a democratic environment as it created a common framework for students to share their learning experiences and professional growth. The instructors agreed that the students needed to take a central role in online discussion while instructors assumed a "facilitator" or "consultant" role to scaffold the discussion. For example, one instructor commented,

I feel comfortable commenting in the discussion forums as just another person who has maybe a little more expertise or a broader view of how a company relates to other companies. And occasionally students would clearly put me in that role. They'd say you know I had this question about your case. I wonder what the professor thinks about that.

Although many agreed on the role of instructor, the range of facilitation showed a wide spectrum of moderating strategies and frequencies of interactions. On the low end, approximately half of the instructors rarely moderated online discussions. On the high end, a few instructors participated extensively in online discourse through a variety of facilitating techniques including questioning, prompting responses, recognizing, requesting responses, and modeling social presence.

Instructors noted several issues that affected the degree of their presence. For instance, a few instructors expressed concerns about not knowing effective moderating strategies to promote peer interaction. As noted by an instructor:

How can I do a more effective discussion forum? Because I'm just going to emphasize it much less this next time unless I feel like I can come up with a good technique.

A few instructors were concerned about the time commitment associated with facilitating online discussion. For instance, one instructor commented:

This is very labor intensive. I'm spending a long time, and it's just a lot of work. Sometimes when I'm away, I don't get broadband. I was teaching in Cancun, Mexico, on a dial-up, it was really slow.

In addition, some instructors were concerned that the authoritarian role of the online instructor might deter a fruitful peer discussion among online learners. As an example, one of those instructors shared the 
following:

I've also found that [if I do not participate,] they're much freer to discuss issues. And I tell them that up front. I say the discussion forum for all practical purposes is your area. That's where you ask your fellow student questions.

Instructors regarded their facilitator role more as a way to best promote peer interactions in an online course than as an opportunity for enhancing student-instructor interaction. The varying degrees of the "facilitator" role reflected divergences in skills, diverse philosophical orientations for teaching online, and the willingness of instructors to commit significant time.

\section{Managerial Role}

With respect to the managerial roles, two areas emerged: (a) Conference manager, and (b) Organizer and planner.

\section{a. Conference Manager}

Ensuring equity in online discussion has been one of the most important managerial concerns. Many instructors noted that the negative effect of time lag in asynchronous discussion could easily cause dominancy issues in discussions because early students can take control of the forum. The following comment demonstrated how an instructor provided guidelines to ensure students' equal opportunities in contributing to the discussion:

So this year, I said you can only contribute on the first day to two of the cases. You can't contribute to all four. Because there were guys in the previous years that would try to beat everybody to the punch on the cases, and answer every question on every case, and it got some of the others upset, so I said, no, you can only post to two. And, I give them some suggestions on these things. You don't have to answer every question. I'm interested in quality, not quantity. This time, they were much more disciplined.

Another issue related to time lag was the reduced responsiveness of online students to peer's comments which resulted in extensive redundant information. To address this issue, some online instructors created specific rules related to not repeating previous comments or ideas. Besides introducing rules, the instructors either introduced more discussion threads at the beginning or introduced new discussion topics in the middle of the discussion to augment the discussion. One instructor commented:

It's one continuous discussion. For example when I introduce the first question they don't know what the second passage is going to look like. So I'll post the first thing and then they'll post and they'll be able to see what everybody else has posted. And when I think things have run out I'll introduce the next one. So it’s very simple. It's just one running discussion.

Though much effort was made to promote interactive discussion, the results revealed that the instructors still had great difficulty in refining and "weaving" discussion so that conversations progressed from sharing answers to knowledge-negotiation and -construction [17].

\section{b. Organizer and Planner}

One important aspect of organizing is to being clearer and more structured when giving directions online. Many instructors found that any ambiguity would result in misunderstanding in communication and thus reduce the efficiency of the learning process. An instructor commented: 
I think you have to be clearer online. If you're not clear in the classroom, a student is going to ask you a question and it'll get conveyed immediately to everybody. So you've got to be a lot more careful online as to how you answer something or ask something, and you've got to be a lot clearer in your direction, clearer in your instruction.

In addition to daily pedagogical concerns, instructors consistently noted the importance of course structure and organization in an online course for planning purposes. The instructors sensed that online learners need to be provided with a clear structure and timeline to keep them engaged in learning in the midst of their busy work schedules. Two instructors commented:

In an online environment they've got control of their calendar essentially as to when they do certain things. The splitting up into weekly modules in part was a recognition that we all tend to put things off if we can, and so having weekly modules with some sort of a deliverable every week puts or forces some structure on them so they can't wait until the last couple of weeks and try to do everything at that point in time.

Instructors' flexibility can help accommodate students' schedules. A number of instructors commented on changing the assignment due date from Sunday to Monday since many students have to spend a great deal of weekend time to work on the assignments.

\section{Social Role: Rapport Builder}

Only one social role emerged in this study, the social rapport builder.

One of the greatest challenges for online learning, as many instructors noted, was the ability to build a more personal relationship between educator and student. The "impersonal nature" of the online environment posed a great difficulty for building social rapport. Examples of the lack of personalization can be seen in the comments of two different instructors:

That's one of the difficulties. It's a very impersonal environment whereas the face-to-face is much more personal. You can develop rapport with students. You see the interaction that's going on between people, and you can use that in a teaching environment. That's much more difficult to do in an online environment, and that's one of the things that I feel is missing from the online environment.

The feedback that we've gotten from the students is that things online feel very impersonal and they never get to know the instructor. And I would agree because I never get to know the students.

Many instructors associated the low social presence in their courses with the limitations of existing technology that was unable to project participants' identity or personality into an online course. To address this issue, the program established a policy to add at least one video introduction of the instructor in each course. Videos helped convey instructor identity but, nevertheless, did not help with the social presence or online identities of students. In fact, only two out of 27 instructors tried to use some simple social ice-breaking activities or introduction forums, allowing students to become familiar with each other and their personal stories. In addition, only three of them used virtual office hours.

With regard to the instructors' role in building a sense of community in an online course, many admitted that they did not feel a sense of community in their courses, nor did they take any measures to build a collective identity in an online course. For instance, one instructor stated: 
So I really encouraged the students to contact me in any way that they felt comfortable. I sort of gave them many options. But as far as creating a sense of "we're all here at this moment," I did not.

However, instead of taking an active role in establishing an online class community, the instructors agreed on their role in establishing online teams and encouraging group knowledge-sharing. Nonetheless, whether the relationship among a group can be projected as a sense of belonging to a class community remained an open question. When asked about a sense of community in his course, an instructor said:

Well, I think it's important. The teams provide an opportunity to do that. Whether or not it has to move to the class level, I'm not so sure.

Several instructors mentioned that the time associated with playing the social role in an online course might detract from time for the pedagogical role. As one instructor commented:

I can socialize with the students and take a tremendous amount of time, and what's that going to come at the expense of? It's going to come at the expense of my quality instruction, making sure that the materials are there. I've got to cut somewhere. I can't be everything to everybody.

In summary, the instructors had mixed feelings regarding the importance of the social role in this online MBA program. In general, these instructors were not yet convinced of the relevance and viability of the social role for student learning. Various technological limitations and concerns about time further detracted from community building efforts.

\section{Technical Role}

With respect to the technical role, three areas emerged:(a) Technical coordinator, (b) Media designer/developer, and (c) Technology integrator.

\section{a. Technical Coordinator}

Their technical role required instructors to refer students to technical support resources or communicate technical issues to support staff. This role was also partly defined by the technical support structure of the program. Each course was supported by a course designer who helped with the operation of the course. Because the course management system in general functioned effectively, sometimes the issue was not really a technological flaw but inappropriate creation of the settings by the instructors or students' insufficient understanding of the mechanics of the tools. Oftentimes, the commercial simulation programs used in the online MBA courses had technical issues that the instructors had to send or forward to technical support staff. As noted by one instructor,

A lot of my students had problems with it [simulation software] last year, and I think that the company that's producing it probably hasn't updated their software. So people get frustrated...

\section{b. Media Designer/Developer}

About half of the instructors reported using multi-media elements in their courses. However, the instructors reacted differently about their roles in using different forms of multimedia in their online courses. Several instructors who had experience in using video tapes in the traditional classroom felt comfortable in converting their videos into digital format. However, a few instructors who had developed video clips from scratch were unsure about whether the anticipated education benefit was worth the extra 
development effort. Two instructors commented:

And I've added some nice features like video clips in there too, which seem to be working pretty well. Those videos have been on VHS format for a while, but for me to deliver them in the classroom from Power Point I had to learn how to digitize and compress, and doing it over the web was just one additional step.

The video clip was a real production which took a great deal of time to create. And students said 'Oh that's okay, that's good. Now, have you graded our papers yet?” That's what they really wanted to know. So in the class, I kept what Camtasia had already done but I'm not going to invest any more time than that.

A number of instructors mentioned the need to identify or develop tools that could improve the efficiency of assessment of and feedback to online students. A few instructors in this program had collaborated with the technical developers through contributing their design ideas. For example, one instructor commented on the ideas of automating the assessment process:

In the $\mathrm{Q}$ and $\mathrm{A}$ forum, I wish that statistics could be collected in a way that was by assignment. All we have right now is statistics on how many times they logged on.

\section{c. Technology Integrator}

One of the most frequently mentioned issues related to the instructors' frustration with the inefficiency of online chat room tools. From the start, almost every instructor tried to use chat rooms for online discussions or virtual office hours. However, a majority of them finally discontinued using the rooms as a discussion tool because of concerns about technological limitations, typing skills, and the difficulty in scheduling a time for class to meet online.

The very first semester I taught a class I did a chat room, a synchronous chat room, and I found it to be not very satisfying. Most of my students found it very unsatisfactory too, and the reason for this is that the technology is very poor. You have this small little window where you have to type in your comments. It takes you a while to type it in, and then you want to really kind of edit it a little bit, because none of us are perfect typists, and everybody at the other end is waiting. ...

Many instructors held positive attitudes toward using the emerging collaborative technologies such as web-based video conferencing and NetMeeting, which could overcome the weakness of text chat tools and further improve the efficiency and effectiveness of online learning. With those tools, it was expected that a better professional intimacy, realism, and real-world flavor for online students could be established. However, when adopting more visually rich and interactive tools, instructors were concerned about accessibility and bandwidth. Examples of those issues can be seen in the following comments:

There's a lot you could do, but the constraint is that the computers at the other end are not what they need to be. I'd love to get on a web cam and have a chat room, but most [students] can’t do that because they don’t have the software or the hardware to do it.

New technologies increased efforts to include highly interactive pedagogical tools. However, the overall level of technology use was still relatively low. Email, asynchronous discussion, and announcements online were the most frequently employed communication tools, whereas more sophisticated interactive tools (such as online synchronous collaborative tools, and multimedia lectures) were in relatively low use. Such findings were consistent with the findings of Peffers and Bloom's study in the late 1990s [28]. 


\section{B. Students' Perceptions of Four Dimensions of Instructor Roles}

In Table 2, selected items from the program evaluation survey reflected students' satisfaction with the four dimensions of instructor roles.

Table 2: Students’ Perceptions of Four Dimensions of Instructor Roles

\begin{tabular}{|c|c|c|c|}
\hline Dimensions & Questions & Mean & Std. \\
\hline \multirow{5}{*}{ Pedagogical } & $\begin{array}{l}\text { The instructors use various instructional techniques for students' critical and } \\
\text { reflective thinking. }\end{array}$ & 3.86 & 0.74 \\
\hline & $\begin{array}{l}\text { The instructors play a role of facilitator, guide, moderator, or coach rather } \\
\text { than that of a lecturer. }\end{array}$ & 4.04 & 0.83 \\
\hline & $\begin{array}{l}\text { The instructors make announcements and give feedback to students on a } \\
\text { regular basis. }\end{array}$ & 3.9 & 0.74 \\
\hline & $\begin{array}{l}\text { Online activities (discussion, role playing, simulations, etc.) in online } \\
\text { courses foster my understanding of key concepts. }\end{array}$ & 4.15 & 0.68 \\
\hline & $\begin{array}{l}\text { I think the way our instructors facilitate the class discussion fosters my } \\
\text { learning. }\end{array}$ & 3.8 & 0.66 \\
\hline \multirow{5}{*}{ Social } & $\begin{array}{l}\text { I feel I am part of a learning community when I take courses in this } \\
\text { program. }\end{array}$ & 4.08 & 0.74 \\
\hline & I never felt lonely or isolated when I took online courses. & 3.44 & 1.07 \\
\hline & $\begin{array}{l}\text { I can see the progress of other students' learning and their outputs in my } \\
\text { online courses. }\end{array}$ & 3.24 & 0.92 \\
\hline & $\begin{array}{l}\text { I can feel the emotions of other students in my online courses through online } \\
\text { interactions. }\end{array}$ & 3.53 & 0.98 \\
\hline & $\begin{array}{l}\text { I feel I know my instructors and other students quite well through online } \\
\text { interactions. }\end{array}$ & 2.89 & 0.95 \\
\hline \multirow{4}{*}{ Managerial } & Directions for projects/assignments in online courses are clear and specific. & 4.1 & 0.74 \\
\hline & $\begin{array}{l}\text { I have easy access to learning resources or materials that I need for my } \\
\text { online courses. }\end{array}$ & 4.13 & 0.66 \\
\hline & Online courses are well organized and presented. & 4.41 & 0.65 \\
\hline & $\begin{array}{l}\text { I feel comfortable reading messages or materials online and discussing with } \\
\text { others online. }\end{array}$ & 4.20 & 0.77 \\
\hline \multirow{4}{*}{ Technical } & $\begin{array}{l}\text { Technologies are used effectively in supporting learning and teaching in } \\
\text { online courses. }\end{array}$ & 3.83 & 0.91 \\
\hline & $\begin{array}{l}\text { The tools/technologies used in online courses (PowerPoint, audio, video, } \\
\text { multimedia and more) are helpful in fostering deep learning. }\end{array}$ & 4.07 & 0.66 \\
\hline & The tools/technologies used in online courses are easy to use. & 4.10 & 0.57 \\
\hline & I am satisfied with the technical support that I receive in this program. & 4.14 & 0.66 \\
\hline
\end{tabular}

\section{Pedagogical Role}

According to the student survey, the students had generally positive experiences with instructors' pedagogical facilitation in this program, and they were highly satisfied with the impact of instructor guidance on their learning experiences. Nearly $80 \%$ of the students agreed that the instructors used a variety of instructional techniques to foster students' critical and reflective thinking. About $90 \%$ of the students agreed that online learning activities fostered their understanding of key concepts. Nearly $85 \%$ of the students agreed that the instructors play a role of "facilitator" rather then a "lecturer." More than 75\% of the students replied that the way the instructors facilitated the class discussion fostered their learning. However, about $20 \%$ were not so sure about the effectiveness of the instructors' facilitation in discussion forums.

\section{Social Role}

The results in Table 2 suggested that the level of social presence in this program was relatively low. In 
effect, the students were not engaged in a fully socially supportive online learning environment. While approximately $60 \%$ of the students never felt lonely while taking the classes, about $25 \%$ did, in fact, feel isolated. In addition, $49 \%$ responded that they could not feel the emotions of other students in their online courses. Similarly, only $28 \%$ of students felt that they knew their instructors and other students well. Although the students felt a low level of social presence in online courses, nearly $90 \%$ indicated they felt they were part of a learning community when they took online courses. These findings indicated that other factors, such as the one week in-residence required by the program to develop group cohesiveness, helped foster a sense of community in online courses in this program.

\section{Managerial Role}

Overall, the students reacted positively to the organization of course materials and were able to efficiently find learning resources in online courses. About $85 \%$ of online students agreed that online instructors provided clear instructions. Nearly $95 \%$ of the students agreed that the online courses were wellorganized. With the effort of online instructors in promoting equity in online participation, nearly nine in ten students felt comfortable participating in online discussion with others.

\section{Technical Role}

Students overall had positive experiences with the technical tools used in online courses and rated the program technical support highly. Slightly more than $85 \%$ of the students agreed that the tools and technologies used in online courses were helpful for deep learning. However, it should be noted that about $11 \%$ of the students did not agree that technologies were effectively used in online courses.

The overall satisfaction of online learners with the quality of online courses in this program was extremely high ( $\mathrm{M}=4.27, \mathrm{SD}=.72)$. About 90 percent of the students in this study felt they learned a lot from taking courses in this online MBA program $(\mathrm{M}=4.33, \mathrm{SD}=0.76)$. In addition, approximately $86 \%$ students agreed that online courses had improved their skills at work $(\mathrm{M}=4.22, \mathrm{SD}=0.73)$.

\section{DISCUSSION}

The findings clarified faculty and student perceptions of the roles of online instructors, and the perceived satisfactions of online students regarding instructor roles. Although the themes presented may not represent all the roles the instructors engaged in, they represented the most important concerns expressed by online instructors in this program. The findings confirmed Berge's [1] assertions that instructors perform different roles in different degrees when teaching online. One aspect of the teaching process may serve dual purposes. For example, the organizational aspect of course design serves both pedagogical purposes (as a way to keep students engaged in the learning materials) and managerial purposes (as a way to present clear expectations). Many roles identified in this paper are similar to those that have been identified in previous research. At the same time, there are some emerging new roles, such as "professioninspirer," that have not been discussed in literature. Based on the findings from this study, a summary of the perceived priority of different roles by online instructors is displayed in Figure 1 (3=High priority, 2=Medium priority, 1=Low priority). 


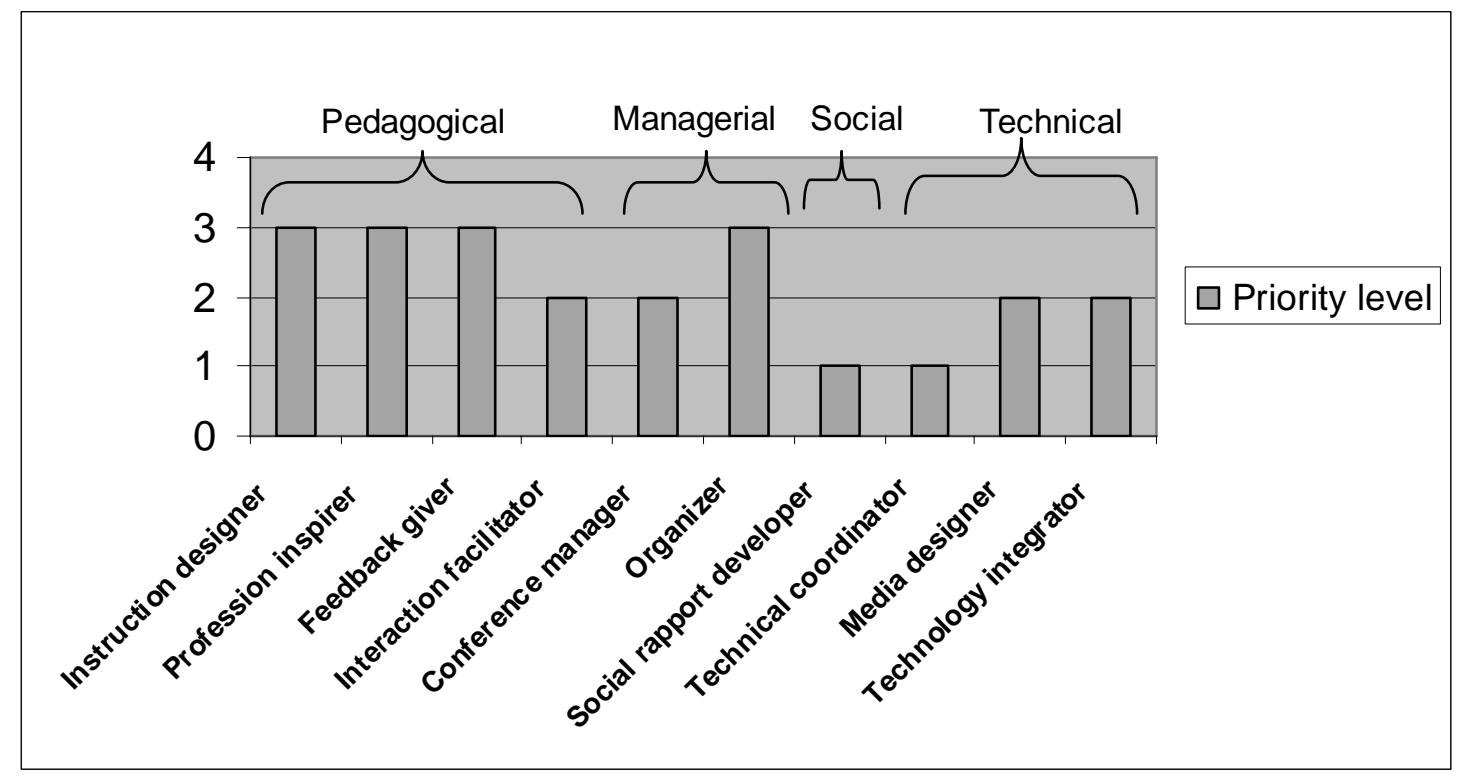

Figure 1. Perceived Priority of Different Roles (High priority=3, Medium priority=2, Low priority=1)

Overall, instructors most strongly emphasize the pedagogical roles. The effectiveness of instructors' pedagogical roles was confirmed by the students' survey. Emphasizing these functions-(1) course design, (2) promoting professional aspirations, (3) providing timely and quality feedback, and (4) facilitating discussion - the instructors promote three key types of interactions online: student-content, student-student, and student-teacher.

It is worth noting that a strong emphasis on the "designer role" represents an important underlying factor in student success. The designer role is also a policy concern in this online MBA program; namely, the importance of ensuring that the learning experience of students in the online environment is roughly equivalent to what students experience in the traditional classroom environment. Based on the results of this study, it is clear that traditional course materials provide a solid knowledge foundation for online courses [29]. However, it was also observed that mimicking traditional classroom strategies can limit the exploration of more innovative learning strategies that can better engage online learners. Many instructors lacked innovative uses of pedagogical and technological techniques in their online courses.

The role of "profession-inspirer" has important implications for professional online educators. Adult learning theory suggests that adult learners come to an online environment with a task-centered orientation and are more ready to learn when experiencing authentic or real-life situations [30]. By participating in workplace-related conversations and dialogues, online learners take ownership of their learning and become more motivated to learn. As learners become inspired for a profession, there is enhanced opportunity for them to form learning communities. Wenger [15], in fact, argued that to learn real-world skills, a successful educator should be able to push the interactions beyond the boundary of a learning community to other communities of practice.

There was a great variance among online instructors on the degree of facilitating online discussion. This study revealed that the variance seemed to associate with a variety of factors (such as timing, course type, perceptions, and moderating skills).There is a need to further explore how and to what degree each of these contextual factors affects instructor presence in online discussion. From this study, there was also an issue as to when to intervene in online discussions. For example, when some instructors found that their 
presence affected discussion flow, they completely withdrew from the discussion. While instructors in this study had shifted their in-class roles from "lecturer" to "facilitator," they need more concrete ideas and strategies about facilitating in a way that does not interfere too much with student learning but still models expertise in content and skill.

The findings related to instructors' perceptions of the social roles were highly similar to those of Conrad's [19] study. As her work demonstrates, there was a general lack of active social role in facilitating a learning community and limited awareness of the possible contributions of the social roles to online learning. Correspondingly, our surveys from students also revealed that the level of social presence in online courses was low. Though the importance of the social dimension of online learning has been increasingly acknowledged in the literature, there is still a gap between the promises and the reality of existing practices in many online programs. This gap will be bridged by acknowledging the fundamental importance of social roles. To assist with this change, there is a need for online instructors to be very explicitly educated and provided with convincing evidence of the relationship between social roles and cognitive learning. Data from this study indicated a need to further explore the relationship between an active social role on the part of the online instructor and learner dynamic.

Another interesting finding regarding social roles is that a majority of students felt a sense of community in spite of the low level of social presence in their courses. We hypothesize that the students' sense of community in online courses came from three different levels of online communities, namely: (1) the small group level, (2) the class level, and (3) the cohort level. Wilson, Ludwidg-Hardman, Thornam, and Dunlap [31] noted that establishing a deep level of collective identity in an online course is difficult due to the brief duration of an online course, unless students have continuous interaction with one another in other courses. They further argued that larger contextual factors such as students' belonging to a program may also be important. This argument suggests that to design online courses for learning community, a more strategic plan needs to be adopted by integrating the measures at these three different levels.

Both roles of "conference manager" or "organizer" emphasize the importance of "structure" (such as procedural rules, clear timeline, and clear directions) for maintaining disciplined participation of online learners. Consistent with previous studies [21, 4], this study supported the notion that instructors perceived the "structure" to be an essential condition for providing a psychologically safe learning environment and sustaining continuous engagement in online learning.

The findings indicate that instructors' technical roles evolved from assisting with technical issues to include identifying or developing online pedagogical tools to address ethical concerns about accessibility. Consistent with prior studies [17, 19, 22], the general technology used in this online MBA program did not present significant challenges to online instructors. Over time, the instructors reported that the technology became increasingly reliable and that the technical support from the organization had become more efficient.

The standard online courseware was criticized as lacking pedagogical tools for assisting knowledge construction, information-seeking and -sharing, debate, and reflection [32]. Nonetheless, the creation of innovative discipline specific pedagogical tools requires close collaboration between online instructors and technical developers. The emerging role of "media designer/developer" suggests the increased proactive attitude of online instructors to participate in designing and developing new pedagogical tools. While there was a sense of excitement and adventure as instructors seemed to be willingly utilizing and learning about new and emerging online technologies, key issues remain about the varying technical skills and lack of knowledge of best practices in technology integration. 
We also noted that the tension between basic accessibility and more sophisticated use of highly interactive learning tools is a significant and growing challenge for technology integration in online learning. We found that when instructors were trying to find the common denominator between high interactivity and accessibility, they often opted to play it safe and try simple tools and activities. Many practical reasons (lack of time, lack of extensive training, and the rapid growth of this program) contributed to conservative choices. There is a need for organizational efforts to provide training and policies which reward online innovation to achieve a higher level of technology use.

Time management was identified as one of the factors that significantly affected the roles and caused significant tensions between different roles. This study reinforced the previous finding that time was consistently ranked as one of the top barriers for teaching online [33]. Time issues indicated not only a need for online instructors to adopt efficient strategies to teach online, but also a need to learn how to strategically unbundle some roles to ease the stress [34]. For example, delegating students to play moderator roles in online discussions or using virtual teaming strategies can not only reduce the workload of online instructors but can also enhance learner accountability while deepening their engagement. Inviting outside experts can enhance the interactivity of an online course with opportunities for real world experience.

Finally, the findings in our study confirmed teacher interaction as one of the most important ways to disseminate distance education information [34]. Teacher interaction is also a key source of assistance and insight that helps teachers through technical and pedagogical challenges [35]. However, the study also suggested that interaction among teachers is limited to the discipline or small groups of people. Wenger's [15] theory suggests such networks need organizational "brokering" (such as regular brown bag lunches and expert consulting) to establish a wider area community so that online instructors can establish a distributed community of practice where all instructors can broadly share their teaching resources and experiences.

\section{CONCLUSION}

Exploration of instructors' roles in this study suggested that the interplay among online instructor roles is very complex. Instructors in this growing program have been successfully playing important roles and providing a satisfactory experience for online learners. However, it was noted that there was extensive variance among online instructors about how they play or perceive their roles in this program. This study also indicated that several prominent contextual factors affected their roles. And there are perceived tensions between different roles. It was encouraging to see online instructors strongly emphasize pedagogical roles to assure quality online education. However, there was also an urgent need to raise awareness about the importance of social roles for more engaging and fruitful online learning environments.

To help online instructors make a successful transition from traditional teaching to online teaching, data from this study indicated a need for institutions not only to plan future roles, but also to provide substantial training support and best practices for implementing those roles [34]. As a program level case study, generalizations from the results in this study may be constrained. However, the analysis of emerging roles, issues, and recommendations raised in this study provide insights to assist distance educators and policy makers to make educational policies and practices for a successful transition for online instructors.

The emerging instructor roles discovered in this research project raise many questions for future research. 
For example, what are the environmental factors affecting instructor's various roles? What is the right balance between instructor presence and student control in online facilitation? Do social roles significantly affect students' learning engagement and in what way? What are effective strategies that can allow instructors to perform social roles and instructional roles concurrently? What roles can be unbundled to students, designers, or support staff given ever-present time pressures in higher education? How can we leverage the tension between interactivity and accessibility in the uses of highly interactive synchronous conference tools? By answering questions such as these, we will be able to better understand the complexity of instructor roles and provide better strategies, advice, and training for online instructors to fulfill their roles.

As MBA programs like this one expand, there will be technological, pedagogical, managerial, and social opportunities that we barely glimpse today. Given the findings of our present study, the online MBA program online is a promising venture, with some room for enhancement. For example, pedagogical agents might help learners view connections between real-world experience and the content they are struggling with. Synchronous conferencing tools might enable students to bring more issues to the attention of their instructors as well as to their peers as they interact and provide just-in-time course feedback. Emerging mobile technologies can further expand the horizon of online learning. At the same time, it is time to think about workplace learning and true apprenticeship possibilities that are available for MBA students and other professional degree students.

\section{REFERENCES}

1. Berge, Z. L. Facilitating Computer Conferencing: Recommendations from the Field. Educational Technology 15(1): 22-30, 1995. http://www.emoderators.com/moderators/teach online.html.

2. Morine-Dershimer, G. What's in a Case and What Comes Out? In Colbert J., K. Trimble, and P. Desberg (Eds.), The Case for Education: Contemporary Approaches to Using the Case Methods, 100-123. Needham Heights, MA: Allyn \& Bacon, 1996.

3. Coppola, N. W., S. R. Hiltz, and N. Rotter. Becoming a Virtual Professor: Pedagogical Roles and ALN. Proceedings of the 34 ${ }^{\text {th }}$ Hawaii International Conference on System Science. Maui, Hawaii, 2001.

4. Heuer, B. P., and K. King. Leading the Band: the Role of the Instructor in Online Learning for Educators. Journal of Interactive Learning Online 3(1): 2004. http://www.ncolr.org/jiol/issues/PDF/3.1.5.pdf.

5. Bonk, C. J. My Hat's on to the Online Instructor. e-Education Advisor: Education Edition 1(1): 1013, 2000.

6. Berge, Z. L. New Roles for Learners and Teachers in Online Education, 2001. http://www.globaled.com/articles/BergeZane2000.pdf

7. Bonk, C. J., R. A. Wisher, and J. Lee. Moderating Learner-centered E-learning: Problems and Solutions, Benefits and Implications. In Roberts, T. S. (Ed.),Online Collaborative Learning: Theory and Practice, 54-85, Hershey, PA: Idea Group Publishing, 2003.

8. Ashton, S., T. Roberts, and L. Teles. Investigation the Role of the Instructor in Collaborative Online Environments. Poster session presented at the CSCL '99 Conference, Stanford University, CA, 1999.

9. Bonk, C. J., J. R. Kirkley, N. Hara, and N. Dennen. Finding the Instructor in Post-secondary Online Learning: Pedagogical, Social, Managerial, and Technological Locations. In Stephenson, J. (Ed.), Teaching and Learning Online: Pedagogies for New Technologies, 76-97, London: Kogan Page, 2001.

10. Salmon, G. E-moderating: The Key to Teaching and Learning Online. London: Kogan Page, 2000.

11. Cummings, J. A. Debate in the Virtual Classroom. Unpublished manuscript, Indiana University at Bloomington, USA, 2000.

12. Johnson, C. M. A Survey of Current Research on Online Communities of Practice. Internet and Higher Education 4(1): 45-60, 2001. 
Exploring Four Dimensions of Online Instructor Roles: A Program Level Case Study

13. Powers, S., and S. Guan. Examining the Range of Student Needs in the Design and Development of a Web-based course. In Abbey, B. (Ed.), Instructional and Cognitive Impacts of Web-based Education, 200-216, Hershey, PA: Idea Group Publishing, 2000.

14. Kerr, E. Electronic Leadership: A Guide to Moderating Online Conferences. IEEE Transactions on Professional Communications 29(1): 12-18, 1986.

15. Wenger, E. Communities of Practice: Learning, Meaning and Identity. London: Cambridge University Press, 1998.

16. Lave, J., and E. Wenger. Situated learning: Legitimate peripheral participation. London: Cambridge University Press, 1991.

17. Anderson, T., L. Rourke, W. Archer, and R. Garrison. Assessing Teaching Presence in Computer Conferencing Context. Journal of Asynchronous Learning Networks 5(2): 1-17, 2001. http://www.sloan-c.org/publications/jaln/v5n2/v5n2_anderson.asp.

18. Eastmond, D. V. Alone but Together: Adult Distance Study through Computer Conferencing, Cresskill, NJ: Hampton Press, 1995.

19. Conrad, D. University Instructors' Reflections on their First Online Teaching Experiences. Journal of Asynchronous Learning Networks 8(2): 31-44, 2004. http://www.sloan-c.org/publications/jaln /v8n2/pdf/v8n2_conrad.pdf.

20. Mason, R. Moderating Educational Conference. DEOSNEWS 1(19): 1998. http://www.emoderators.com/papers/mason.html.

21. Pincas, A. Successful Online Course Design: Virtual Frameworks for Discourse Construction. Educational Technology and Society 1(1): 1998. http://www.ifets.info/journals/1_1/pincas.html.

22. Teles L., S. Ashton, T. Roberts, and I. Tzoneva. The Role of the Instructor in E-Learning Collaborative Environments. TechKnowlogia 6/7, 2001.

23. Hara, N., and R. Kling. Students' Distress with a Web-based Distance Education Course: An Ethnographic Study of Participants' Experiences. Information, Communication \& Society 3(4): 557579, 2000.

24. Kanuka, H and C. Caswell. University Instructor's Perceptions of the Use of Asynchronous Textbased Discussion in Distance Education. The American Journal of Distance Education 16(3): 151167, 2002.

25. Stake, R. Case Studies. In Denzin, N. K. and Y. S. Lincoln (Eds.), Handbook of Qualitative Research. Thousand Oaks, CA: Sage, 1994.

26. Merriam, S. B. Case Study Research in Education: A Qualitative Approach. San Francisco, CA: Jossey-Bass Publishers, 1998.

27. Miles, M. B., and A. M. Huberman. Qualitative Data Analysis, 2nd ed. Thousand Oaks, CA: SAGE, 1994.

28. Peffers, K. and S. Bloom. Internet-based Innovation for Teaching IS Courses: The State of Adoption: 1998-2000, Journal of Information Technology Theory and Applications 1(1): 1999.

29. Salmon, G., and K. Giles. Moderating Online, 1997. http://www.emoderators.com/moderators/gilly/MOD.html.

30. Knowles, M. S. Adult learning. In Craig, R. L. (Ed.), ASTD Training \& Development Handbook: A Guide to Human Resource Development. New York: McGraw Hill. 1996.

31. Wilson, B., S. Ludwidg-Hardman, C. L. Thornam, and J. C. Dunlap. Bounded Community:Designing and Facilitating Learning Communities in Formal Courses. Paper presented at the meeting of the American Educational Research Association, San Diego, CA, 2004. http://carbon.cudenver.edu/ bwilson/BLCs.html.

32. Bonk, C. J., and V. Dennen. Frameworks for Research, Design, Benchmarks, Training, and Pedagogy in Web-based Distance Education. In Moore, M. G. and W. G. Anderson (Eds.), Handbook of Distance Education. Mahwah, NJ: Erlbaum. 2003.

33. Berge, Z.L. and L. Y. Muilenburg. Obstacles Faced at Various Stage of Capability Regarding Distance Education in Institutions of Higher Education. Tech Trends 46(4): 40-45, 2001. 
34. Howell, S.T., F. Saba, N. K. Lindsay, and P. B. Williams. Seven Strategies for Enabling Faculty Success in Distance Education. Internet and Higher Education 7(1): 33-49, 2004.

35. Anderson, T. Modes of Interaction in Distance Education: Recent Developments and Research Questions. In Moore, M. G. and W. G. Anderson (Eds.), Handbook of Distance Education. Mahwah, NJ: Erlbaum, 2003.

\section{ACKNOWLEDGEMENTS}

A previous version of this paper has been accepted for presentation in 2005 American Education and Communication Technology (AECT) International Conference. We would also like to acknowledge help from a group of other researchers who contributed in collecting data for this project:

- Shi, Min, Ph.D., School of Education, Indiana University

- Kim, Kyong-Jee, Doctoral Candidate, School of Education, Indiana University

- Liu, Shijuan, Doctoral Candidate, School of Education, Indiana University

- Zhai, Mengyu, Doctoral Student, School of Education, Indiana University

\section{ABOUT THE AUTHORS}

Xiaojing Liu is a Ph.D. candidate in Instructional Systems Technology and a research fellow at Kelley Direct Online Program at Indiana University, Bloomington. Her research interest focuses on online learning, information systems, communities of practices, and knowledge management.

Curt J. Bonk is a Professor of Instructional Systems Technology at Indiana University. Dr. Bonk is also a Senior Research Fellow with the DOD's Advanced Distributed Learning Lab. He has received the CyberStar Award from the Indiana Information Technology Association, Most Outstanding Achievement Award from the U.S. Distance Learning Association, and Most Innovative Teaching in a Distance Education Program from the State of Indiana. Dr. Bonk is in high demand as a conference keynote speaker and workshop presenter. He is President of CourseShare and SurveyShare. More information about Dr. Bonk is available at http://mypage.iu.edu/ cjbonk/.

Richard J. Magjuka is a professor of business administration in the Kelley School of Business. He has been the faculty chair of Kelley Direct since its inception. His primary research interests are the design and delivery of effective online education and in online pedagogy. He received his undergraduate degree from the University of Notre Dame and his Ph.D. from the University of Chicago.

Seung-hee Lee is a researcher at Kelley Direct Online Program within Kelley School of Business at Indiana University. Dr. Lee earned her doctorate from Hanyang University in Seoul, Korea, in 2003. She worked as a postdoctoral research fellow at Indiana University for one year from September 2003December 2004. Previously, she had worked in the Center of Learning and Teaching of Korean National Open University in Seoul, where she consulted, working to promote faculty development, instructional design, and development for e-learning. Major research interests of Dr. Lee are online collaboration, reflective technologies, e-learning in higher education, and online moderating/mentoring.

Bude Su is a Ph.D. candidate in Instructional Systems Technology and works as the Assistant Web director of School of Education in Indiana University Bloomington. She is also a research fellow at Kelley Direct Online MBA program at Indiana University. Previously she was the National Director of International Education and Resource Network in China (http://www.iearn.org). Her major research interests include online teaching and learning, technology integration in education, organizational behavior, and knowledge management. 